\title{
La introducción e influencia del manga en México: El caso de Lorena Velasco Terán y DREM
}

\author{
Sarahi Isuki Castelli Olvera
}

Universidad Autónoma del Estado de Hidalgo

Sarahi Isuki Castelli Olvera es Doctora en Ciencias Sociales con área de énfasis en Historia. Es profesora en el área Académica de Historia y Antropología de UAEH. Ha trabajado en el análisis de la imagen desde la perspectiva de la Historia y la cultura visual. Destacan los temas de ponencias relacionados con arte contemporáneo, cómic japonés e historieta mexicana. Entre sus últimas publicaciones destacan los siguientes títulos: Reconfiguraciones de la identidad de género en películas infantiles. Caso de estudio: Valiente, en coautoría con la Dra. Azul Kikey Castelli Olvera (2013); y Apocalipsis en clave manga. Un análisis semiótico de X, un cómic japonés, en coautoría con la Dra. Thelma Camacho Morfín (2015).

Fecha de recepción: 23 de abril de 2016

Fecha de aceptación definitiva: 20 de mayo de 2016 


\title{
Resumen
}

En este artículo analizamos la influencia del manga japonés en la creación de productos mexicanos que retoman su estética. Realizamos un análisis de DREM, cómic creado y publicado en 2008 por Lorena Velasco Terán. DREM retoma la gráfica del manga y fórmula de comercialización. Fundamentamos lo anterior con base en lo siguiente: el manga entró a México en un momento en el que la apertura de fronteras permitió su libre introducción. Entraron primero los videojuegos y anime, que familiarizaron al público con la estética del manga. La autora de DREM retomó dos aspectos: su gráfica y modo de comercialización.

Palabras clave: manga, habitus, campo, manga mexicano, convenciones de cómics

\begin{abstract}
In this article we analyze the influence of Japanese manga in the creation of Mexican products that return to their aesthetics. We did a DREM analysis, comic created and published in 2008 by Lorena Velasco Terán. DREM retakes the sleeve graph and marketing formula. We base the above based on the following: The manga entered Mexico at a time when the opening of borders allowed its free introduction. Entered the video games and anime, which familiarized the audience with the aesthetics of manga. The author of DREM took up two aspects: its graph and mode of commercialization.
\end{abstract}

Keywords: manga, habitus, field, Mexican manga, comic conventions

\section{Cita bibliográfica}

Castelli Olvera, S. I. «La introducción e influencia del manga en México: El caso de Lorena Velasco Terán y DREM», en CuCo, Cuadernos de cómic n. 8 (2017), pp. 31-53. 
En este artículo partimos de la consideración de que DREM, manga mexicano creado en 2008 por la diseñadora Lorena Velasco Terán, mezcla la gráfica del manga japonés además de su fórmula de comercialización. Fundamentamos lo anterior con base en las siguientes premisas: primero, el manga y sus productos relacionados entraron a México en un momento en el que la apertura de fronteras producto de la aplicación del modelo neoliberal permitió su libre introducción al país. Segundo, a México entraron primero los videojuegos y el anime, productos que familiarizaron al público con la estética del manga en las convenciones de cómics. Finalmente la autora de DREM retomó dos aspectos: la gráfica del manga y su modo de comercialización, mismos que conoció y desarrolló dentro del ámbito de las convenciones.

Sostenemos lo anterior con base en la noción de campo de Pierre Bourdieu, quien plantea que el espacio social está integrado por una serie de campos dentro de los cuales, los agentes mantienen relaciones de oposición por mantener o acceder a los diversos tipos de capital. ${ }^{1}$ Por otra parte, retomaremos la propuesta de Omar Calabrese, quien sistematiza las características actuales de las manifestaciones culturales, en donde lo irregular, la repetición, la cita, el fragmento y el detalle son lugares comunes de la cultura actual. ${ }^{2}$

A diferencia de la propuesta de Hiroki Azuma y Eiji Otsuka, quienes sostienen que la producción actual de mercancía produce un consumo irracional que encamina al hombre a la animalización, ${ }^{3}$ nuestro planteamiento se basa en el supuesto de que existe un consumo racional del producto y el público reelabora, reinterpreta y recrea los elementos que se le presentan, lo que genera nuevos elementos que son producto del proceso de hibridez entre la narrativa y gráfica japonesa en conjunto con las tradiciones locales.

Las fuentes primarias de esta propuesta son los siete fascículos de DREM así como entrevistas a la autora. Las fuentes secundarias fueron artículos académicos y la bibliografía sobre el tema del manga dentro y fuera de Japón.

\section{La historieta en México}

Al igual que Japón, México cuenta con una larga tradición en la elaboración de historietas. Las primeras tiras cómicas se publicaron en periódicos y se basaban en creaciones estadou-

\footnotetext{
${ }^{1}$ Bourdieu, P. El sentido social del gusto, elementos para una sociología de la cultura. Buenos Aires, Siglo xxi, 2010.

2 Calabrese, O. La era neobarroca. Madrid, Cátedra, 1999.

3 Azuma, H. Otaku. Animal database. Minessota, Universidad de Minessota, 2009.
} 
nidenses; sin embargo, la poca regularidad con la que llegaban, originaron que se independizaran de los periódicos y se impulsara su producción local. Se conoce como era dorada de la historieta mexicana al periodo comprendido entre las décadas de los treinta y cincuenta, momento en el que se vendían en formatos misceláneos, la historia continuaba en cada número y se imprimían millones de ejemplares diariamente. En la década de los setenta inició lo que se conoce como era de plata de la historieta mexicana, sus tirajes se volvieron semanales y surgió el formato novelado.

En los ochenta iniciaron las transformaciones en su consumo debido a varios factores: "por un lado sus temáticas resultaban pasadas de moda, la industria parecía cerrada a nuevas propuestas además de la fuerte censura y las malas condiciones en las que laboraban los creadores.» ${ }^{4}$ Aunado a lo anterior, la crisis económica en la que estaba sumido el país generó desabasto de papel y pérdida de poder adquisitivo. ${ }^{5}$ Finalmente, en este periodo se dio la introducción paulatina de nuevos productos de entretenimiento debido a la apertura de fronteras, propia de la implantación de las políticas neoliberales en el país: en 1986, México se adhirió al Acuerdo General de Aranceles Aduaneros y Comercio (GATT) y en 1994 entró el vigor el Tratado de Libre Comercio de América del Norte (TLCAN).

Los factores anteriores hicieron evidente que la historieta industrial ya no era rentable y precipitaron su decadencia. En esta década entraron a México el anime y el manga, y en 1994 iniciaron las primeras convenciones de cómics. El acceso a historieta extranjera nutrió y permitió el auge de la historieta de autor como Gallito Cómics, el Fanzine del Colectivo Molotov y más tarde las publicaciones del Taller del Perro.

\section{La estética y consumo de manga en los noventa}

El manga entró a México precedido de los videojuegos y el anime, acompañado del merchandising, ${ }^{6}$ elementos que familiarizaron al público con su estética al exhibirse en espacios de consumo y producción de cómics en la ciudad de México. Dichos espacios son lugares en los que los aficionados tenían acceso al cómic, manga y productos relacionados. También se podía pagar por espacios para difundir creaciones propias; se podía aprender la dinámica de las convenciones, las estrategias de venta, producción y permanencia dentro del lugar. Por

${ }^{4}$ Gantús, L. La increible y triste historia de la cándida historieta y la industria desalmada. México, Gantús Producciones, 2014.

5 Camacho Morfín, T. «Dibujar historietas. Una enseñanza fuera de la Academia,» en De Los Reyes, A. (coord). La enseñanza del dibujo en México. México, Universidad Autónoma de Aguascalientes, 2014, p. 341.

${ }^{6}$ «Merchandising es el conjunto de técnicas puestas en práctica, de forma separada o conjunta, por distribuidores y fabricantes, con miras a acrecentar la rentabilidad del punto de venta, dar mayor salida a los productos, y la introducción de productos.» Ramírez BeLtrán, C. J. «Modelo conceptual para determinar el impacto del merchandising visual en la toma de decisiones de compra en el punto de venta», en Pensamiento y gestión, n. 36 (2014), p.5. En el caso del manga, el merchandising se relaciona con toda la serie de productos como ropa, pósteres, figuras de acción, etcétera. que retoman la estética y los personajes de una determinada serie. 
lo general, se podía comprar y difundir cómics, animación y productos relacionados en dos espacios: las convenciones y las tiendas especializadas.

Las convenciones de cómics son eventos organizados con finalidad de entretenimiento y comercio. En estos espacios circulan cómics y productos relacionados, se organizan juegos, concursos, se exhibe el trabajo de artistas locales y extranjeros. Por lo general, las convenciones se componen de una zona de exhibidores y promotores, una zona de empresas y patrocinadores, un área de artistas y un área de comida. La primera convención de historietas en la ciudad de México fue la Conque, organizada en 1994 por el promotor de cómics Luis Gantús. Además de la anterior, en dicha década destacan MECYF, TNT, la Mole, Mangacon, Comictlan y las Jornadas de Anime, rol y videojuegos Tsunami, las cuales, en su mayoría, se llevaban a cabo en el Centro de Convenciones Tlatelolco, el Wall Trade Center, entre otros.

En la Ciudad de México en la década de los noventa, también había tiendas que surtían a los aficionados de material actualizado, nuevo y legal, como Mundo cómics. Por su parte, la Casa de la Caricatura popularizó el manga debido al material de importación que comercializaban; además organizaban tardes de anime y conferencias con actores de doblaje. ${ }^{7} \mathrm{~A}$ los lugares antes mencionados, se agregan Cómic Castle y Revoltijo, ambas tiendas ubicadas en el sur de la Ciudad de México, donde tradicionalmente se centra la oferta cultural.

El tipo de interacción que se da entre los sujetos que integran estos espacios de intercambio, producción y circulación de cómics, particularmente en las convenciones, se asocia con el campo consumo cultural mexicano del que forman parte. Para entender su dinámica, necesitamos recurrir a la categoría campo propuesta por Bourdieu, para quien el espacio social está integrado por una serie de campos autónomos dentro de los cuales, los agentes mantienen relaciones de oposición por mantener o acceder a los diversos tipos de capital: económico, social, cultural y simbólico o prestigio. El entretejido social, está constituido por aspectos materiales, sociales y simbólicos que se estructuran a partir de la posición ocupada en el campo, a mayor capital, mayor poder y capacidad de dominar al otro.

Un concepto nodal dentro de esta propuesta es el de babitus, el cual se forma cuando un determinado agente, vive, crece, socializa y se relaciona con determinados entornos, contextos y productos de acuerdo con la posición que ocupa en el campo, estas estructuras sociales externas con las que tiene contacto

contribuyen a la producción del sentido subjetivo del mundo en el individuo: sus ideas, creencias, posturas frente al mundo se relacionan estrechamente con la posición ocupada en un tiempo relativamente prologado en un campo determinado, generando una disposición de preferencias y elecciones frente a la oferta social de bienes materiales y culturales. A esta disposición se le llama habitus. ${ }^{8}$ '

\footnotetext{
7 Arceo, M. «La primera dama del manga en México - Heidi, un muestrario de temperamentos» en Santos Cómics, 21 de junio 2016. Disponible en https://rompeviento.tv/?p=9993

8 Cerón Martínez, U. «Reconocimiento simbólico y poder en la obra de Pierre Bourdieu. El juego de las acreditaciones», en Revista de Investigación en Ciencias Sociales y Humanidades Cinteotln. ${ }^{\circ} 1$ (mayo de 2007), p. 5.
} 
De manera que las elecciones que cada individuo realiza, sus gustos, los productos que elige, el consumo cultural que le es propio, están también determinados por su posición en el campo, por lo tanto, el agente tiene una tendencia a elegir determinados productos y otros no, aunque el babitus no es definitivo y pueda cambiar. ${ }^{9}$

Para comprender lo anterior, y a manera de metáfora, podemos entender al campo como un campo de fútbol, en donde sus jugadores equivaldrían a los agentes, los cuales juegan de acuerdo al habitus adquirido en su posición dentro del mismo y para obtener capital en vez del gol. En las convenciones de cómics, el campo estaría igualmente dividido en dos: de un lado las empresas y de otro, los creadores; los primeros tendrían un babitus orientado a acciones que buscan el capital económico. El habitus de los creadores, por su parte, detonaría acciones orientadas a la obtención de capital simbólico o prestigio, en su mayoría, aunque también deben competir con las empresas por capital económico si quieren sobrevivir en las convenciones.

El contacto y desenvolvimiento dentro de las convenciones contribuyó a su vez a generar el habitus de los aficionados, que posteriormente se convertirían en creadores, debido a que estuvieron en contacto con el manga, anime, videojuegos y toda una serie de productos de merchandising. Estos objetos e imágenes fragmentarias constituyeron parte del habitus de aficionados y creadores; fragmentarias porque dichos productos llegan a México sin que el aficionado sepa o pueda reconocer el contexto de creación en primera instancia. «La geometría del fragmento es una ruptura en la que las líneas de frontera deben considerarse como motivadas por fuerzas (por ejemplo fuerzas físicas) que han producido el "accidente" que han aislado el fragmento de su todo de pertenencia. $»^{10}$ De manera que en el caso del manga y sus productos relacionados, las fuerzas que provocan esa ruptura son: la separación del país de origen, de las relaciones y alusiones contextuales, del entendimiento y cultura japonesa, ya que para un fan mexicano, el contenido de un manga, en primera instancia, puede ser interesante, complejo o fantástico pero no necesariamente debe entenderlo dentro de su contexto sin una investigación previa.

\section{Lorena Velasco Terán y Estudio Syanne, manga y merchandising a la mexicana}

Al desarrollarse en el ámbito de las convenciones de cómics, Lorena Velasco Terán, autora del manga mexicano DREM, retomó y reelaboró dos aspectos principales: por un lado, desarrolló una historia propia que retoma la gráfica y convención narrativa del manga, pero sitúa las acciones en la Ciudad de México. Por otro, reprodujo la fórmula de venta del manga e innovó estrategias que le permitieron obtener capital económico a la par del simbólico, dentro de las convenciones.

\footnotetext{
${ }_{9}$ Bourdieu, P. Las estrategias de la reproducción social. México, Siglo xxi, 2011.

10 Calabrese, O. Op.cit., p. 89.
} 


\subsection{DREM, un manga mexicano}

$D R E M$ se centra en Neve, una estudiante de preparatoria quien, al sufrir la pérdida de su madre, crea un sueño para evadir la realidad; dentro de la fantasía, Neve se encuentra en un ambiente escolar estable que ocasionalmente se ve interrumpido por pesadillas y fantasías. La narración finaliza cuando la protagonista logra despertar y aceptar los hechos. Analizaremos esta historieta en dos fases, primero el discurso, que corresponde al modo en que se transmite la historia: ${ }^{11}$ aquí examinaremos su formato y los aspectos gráficos que hacen de $D R E M$ un manga. En la segunda parte analizaremos la diégesis, la cual es la historia pura que contiene un relato, ${ }^{12}$ que abordaremos con un análisis semiótico.

$D R E M$ es una historieta con características de manga, con el que comparte un tipo de dibujo similar en blanco y negro, además de otras convenciones en las que profundizaremos en páginas más adelante. De la historieta mexicana mantiene el formato tamaño carta, las portadas a color, los nombres occidentales de los personajes y el entorno en el que se desarrolla la historia, que es la Ciudad de México en el año 2008.

Este manga mexicano es una saga desarrollada en siete episodios divididos en la misma cantidad de volúmenes. Es una publicación independiente que salió a la venta de manera irregular con intervalos mínimos de dos meses y máximo de cinco, formato tamaño carta con interiores en blanco y negro, el número de páginas variaba de acuerdo a cada volumen, pero oscilaban entre cuarenta y sesenta. El estilo de dibujo corresponde al utilizado por el manga shojo, ${ }^{13}$ por lo que encontramos personajes con rasgos minimalistas y altamente expresivos, lo que se traduce en ojos que ocupan casi la mitad del rostro, con la nariz y boca muy pequeñas sugeridas con líneas. Pese a que este cómic mexicano comparte con el manga el dibujo y el entintado en blanco y negro, se lee de izquierda a derecha y de arriba abajo, según los cánones occidentales de lectura de historieta.

Los tamaños y formas de las viñetas son variados, llegan a ocupar un par de páginas para mostrar un encuadre panorámico o solamente para dejar ese espacio en negro y denotar la transición entre una escena y otra. Debido a que la historia se desarrolla en su mayoría dentro del sueño de Neve, no se usa ninguna distinción para denotar el paso de la realidad al mismo, solamente en el tomo número 7, cuando Neve y el espectador están enterados del sueño, las partes en donde se desarrolla este se trabajan con tintas grises sin altos contrastes.

La línea negra que delimita la viñeta, por lo general, no tiene relevancia significativa o lingüística, sin embargo, hay ocasiones en las que se presenta craquelada o rompiéndose, sobre todo en escenas en donde Neve sufre cuando una serie de cristales salen de su espalda lasti-

\footnotetext{
${ }_{11}$ Montiel, A. Teorías del cine, el reino de las sombras. Barcelona, Literatura y Ciencia, 1999, p. 99.

12 Idem.

${ }^{13}$ Manga dirigido a mujeres adolescentes.
} 
mándola. En cuanto al encuadre, ${ }^{14}$ predomina el uso de planos generales, que muestran los espacios en donde se desarrollan las escenas, los medium shots que muestran a los personajes de la cintura para arriba son los que predominan en las representaciones gráficas, aunque también es muy frecuente el uso del close up y el big close up, los insert o detalles se enfocan por lo general en un ojo o en las manos; otro plano usado con frecuencia en los encuadres es el two shot, cuando se enfoca a dos personajes, como Neve y su amiga Leely, o Neve y su novio Noah.

Además de lo anterior, se observa el uso de balloons (o globos) y onomatopeyas. En cuanto a los primeros, se usan con los bordes dentados para denotar emoción o gritos, se omite el uso del dream balloon para enmarcar los pensamientos de los personajes, y en su lugar se usan los globos coloreados en negro cuando los pensamientos son sombríos o tristes, en relación a esto, se llega a usar una página entera coloreada en negro para colocar ahí los pensamientos. En cuanto a las onomatopeyas, pese a ser un manga, no se utilizan las convenciones propias de Japón, sino las del idioma español, así que vemos la historia plagada de onomatopeyas como tic tac, para el sonido de las manecillas del reloj, el riiing del teléfono, el pip, pip para anunciar el corte de una llamada de teléfono, el pak para simular el sonido de una puerta cerrándose con violencia, tap, tap para el sonido de los pasos, etcétera.

Las hasta aquí descritas e identificadas son convenciones occidentales de elementos que integran el cómic y la historieta, y que también se ven presentes en el manga, por ser elementos básicos que constituyen este tipos de narraciones gráficas; a continuación examinaremos las particularidades de manga que se ven presentes en DREM.

El manga japonés, es por sí mismo un híbrido que retoma diversos aspectos: primero, la tradición gráfica japonesa antigua; segundo, las convenciones occidentales de los cómics introducidas a Japón; tercero, el minimalismo propio del constructivismo ruso; finalmente, se observa el uso de tomas cinematográficas para agilizar la narración. Estos elementos fueron retomados y difundidos por Tezuka en la década de los sesenta, aunque ya habían sido introducidos a Japón desde la década de los treinta y usado en animaciones bélicas. ${ }^{15}$

${ }_{14}$ Es una delimitación bidimensional del espacio. Se refiere a dos órdenes de espacio distintos: el de la superficie de papel en el que se dibuja o imprime la viñeta y el espacio figurativamente representado por el dibujante. Al primero se le denomina espacio real, al segundo espacio ideal. McCloud, S. El arte invisible. Bilbao, Astiberri Ediciones, 2007. p. 124.

15 Para Eiji Otsuka, la introducción de tomas cinematográficas dentro del manga, se dio en el contexto de la II Guerra mundial, momento anterior al trabajo de Osamu Tezuka. Otsuka propone que «la unificación estética de Eisenstein y Disney, bajo las condiciones del fascismo, son el origen del manga y la animación japonesa que hoy todos asocian con la tradición japonesa». Desde este planteamiento, los orígenes del manga moderno, que inicialmente se le atribuían a Tezuka, pueden rastrearse desde la década de los 30, cuando el constructivismo ruso, la teoría cinematográfica de Eisenstein y las animaciones de Mickey Mouse se difundieron de manera simultánea y amplia en Japón, Otsuka Eiji explica que las vanguardias artísticas europeas entraron a Japón en el último lapso de la década de los veinte y cita a Murayama Tomoyoshi cuando afirma que cobraron auge en el ámbito de la pintura y el dibujo. Se entendía que el constructivismo abarcaba los siguientes ámbitos: «a) Americanismo, b) formas de expresión mecanizada destinada a las masas, (c) la glorificación de lo mecánico, y d) formas de expresión constructivista con diseños geométricos y materiales». Bajo estos planteamientos, los 
Uno de los elementos característicos del manga es la supremacía de la imagen sobre el texto, Santiago Iglesias afirma que esto tiene sus raíces en la misma naturaleza icónica de lenguaje japonés, basado en ideogramas; además expresa que la manera de entender el manga y el anime nace de las estampas y grabados japoneses del siglo xIx. ${ }^{16}$ En $D R E M$ se ve presente dicha tendencia que subordina el texto a las imágenes, ya que las escenas de acción llegan a ocupar más de una página e incluso en algunas ocasiones presentan la fragmentación simultánea de la misma escena con muy poco texto.

$D R E M$ retoma del shojo el uso de diversos elementos para subrayar la expresividad en las emociones del sujeto o el momento que vive; por ejemplo, se observa el uso de guirnaldas, flores, corazones, espirales y distintos elementos colocados flotando en el ambiente. Además, se representan figuras femeninas espigadas con largos cabellos, cuyo rostro está compuesto por «ojos inmensos en cuyas pupilas se encienden diminutas estrellas». ${ }^{17}$ Se recurre a la simplificación extrema en el rostro y cuerpo de los personajes con la finalidad de resaltar vergüenza, preocupación, burla, etcétera., debido a que «los rostros minimalistas del shojo y del shonen ${ }^{18}$ han sido concebidos a fin de facilitar al máximo la expresión gráfica de los sentimientos y las emociones inscritas en sus inmensos ojos redondos». ${ }^{19}$

La línea cinética es una de las características principales del manga, aunque no exclusiva del mismo; se ve presente con la finalidad de expresar movimiento y acentuar momentos de tensión emocional en la historia. Es usada por los mangakas ${ }^{20}$ todo el tiempo, incluso

dibujos Mickey, que entraron masivamente a Japón en la década de los treinta, parecían «dibujos basados en la construcción geométrica», por lo que se aproximó la figura de ese personaje de Disney al marco de «construcción»; Otsuka expresa que dicha «disneyficaciación de las expresiones del manga» implicó una ruptura radical con las formas tradicionales de expresión.

En cuanto a la teoría cinematográfica de Eisenstein, fue ampliamente difundida y aceptada en Japón en la misma década. En este contexto, Taihei Imamura, teórico y crítico de cine, defendió la idea de que los rollos de pintura de los mitos del Kojiki, estaban construidos en concordancia a las técnicas cinematográficas, como el close up y el montaje. Imamura estaba fascinado por el marxismo, la vanguardia rusa y Disney, a pesar de que más adelante se desligaría del marxismo, su fascinación por Disney continuaría al punto de seguir escribiendo sobre ello cuando la guerra estalló y las películas norteamericanas se prohibieron. Otsuka apunta que quizás es debido a la relación que hace Imamura de los dibujos de Disney como arma de guerra, que el departamento naval japonés ordenó la producción de films animados. «Esto hizo posible producir animación utilizando las técnicas de Disney acorde con la teoría cinematográfica de Einsenstein». Ejemplo de lo anterior fue el film Momotaro: Umi no Shinpei, producido bajo la dirección del departamento Naval. Desde este enfoque, si bien Tezuka no inventó el uso de técnicas cinematográficas y dibujos basados en Disney en el manga, sí es el responsable de «traer la técnica cinematográfica al manga de la posguerra» Otsuka, E. «An Unholy Alliance of Eisenstein and Disney: the fascist origins of Otaku Culture,» en Research Gate n. ${ }^{\circ} 4$ (febrero de 2016), pp. 253-267. Traducción propia. Disponible en https:/www.researchgate.net/publication/259749564_An_Unholy Alliance of Eisenstein and Disney The Fascist Origins of Otaku Culture

${ }^{16}$ Santiago Iglesias, J. A. Manga, del cuadro flotante a la viñeta japonesa. Pontevedra, Grupo de Investigación dX5 Digital y Grafic Art Research, 2010, p. 134.

17 Ibid., p.186.

18 Manga dirigido a hombres adolescentes.

19 Bouissou, J. M. Manga. Historie et univers de la bande desinée japonaise. París, Philippe Picquier, 2010, p. 181.

${ }^{20}$ Dibujantes de manga 


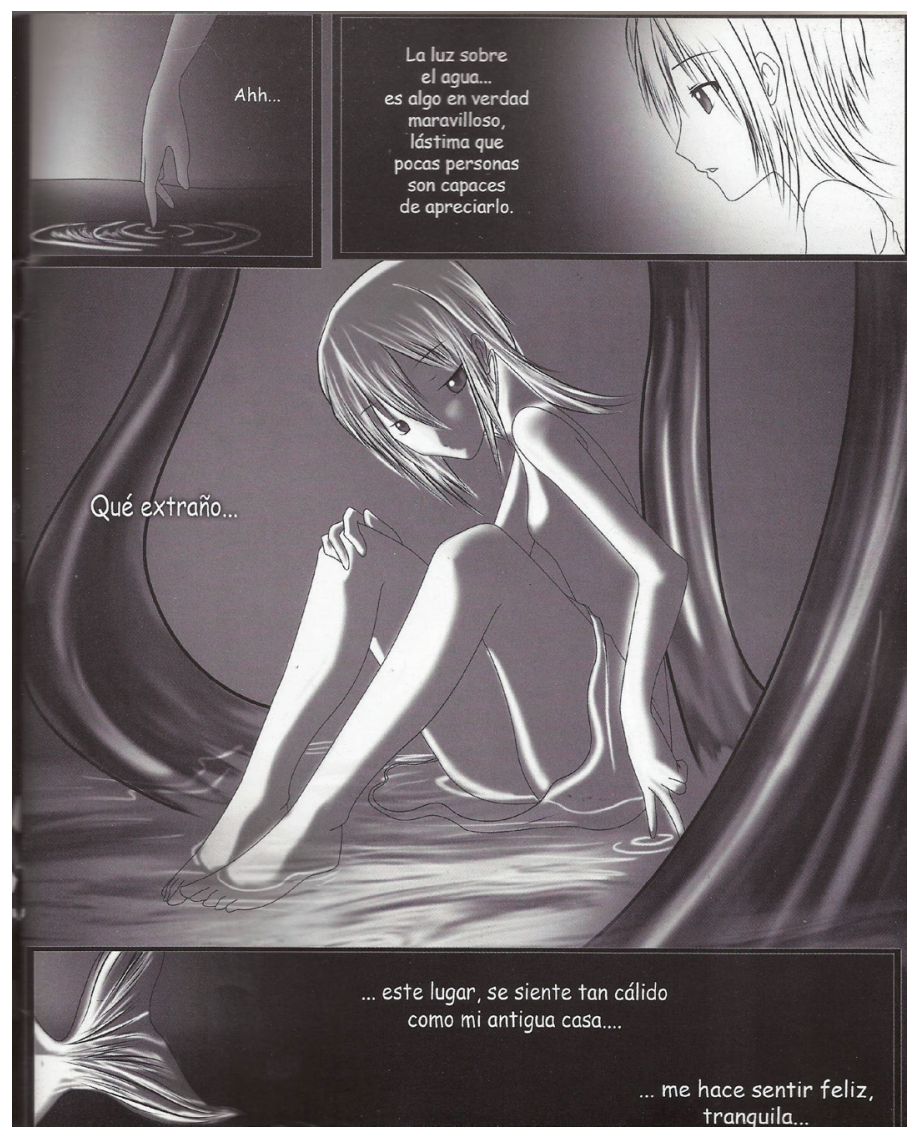

FIG. 1. Velasco Terán, L. DREM, 2008.

con fines decorativos. Además de lo anterior, DREM retoma del manga el uso del vacío representado con fondos en negro, y se da la representación simultánea desde varios puntos de vista. En síntesis, toda la gráfica de DREM se encuentra diseñada en relación con la convención del manga, y lo que se retoma del cómic o historieta occidental, va más en el tenor de los elementos que el manga tomó para sí a partir de la década de los treinta del siglo xx, cuando empezó a reestructurarse y se formó como un fenómeno moderno, de la mano del ya mencionado Osamu Tezuka.

Lo anteriormente descrito, se relaciona con el discurso con el que se construyó el manga; a continuación analizaremos los aspectos que forman parte de la diégesis, los cuales analizaremos a partir de la metodología de Jenaro Talens, quien retoma de Charles Pierce los tres niveles de funcionamiento del signo: sintáctico, semántico y pragmático. ${ }^{21}$ Examinaremos dichos niveles a través de las acciones de los personajes entre sí, dependiendo de su respectivo papel; dichas acciones se denominan funciones o unidades de sentido. ${ }^{22}$

\footnotetext{
${ }^{21}$ Talens, J. «Práctica artística y producción significante», en Elementos para una semiótica del texto artístico, Madrid, Cátedra, 1988.

${ }^{22}$ Las funciones o unidades de sentido, se clasifican en dos grandes grupos: las distribucionales y las integrativas. Las primeras a su vez se dividen en dos más: nudos y catálisis. Las funciones integrativas se dividen a
} 
El nivel semántico analiza el significado de los signos, ${ }^{23}$ aquí se examinan las funciones integrativas (informaciones e índices) que nos proporcionarán datos acerca del espacio-tiempo en el que se desarrolla la historia, además de las características físicas y psicológicas del protagonista y sus relaciones con otros personajes a lo largo del primer episodio.

Las informaciones sirven para identificar y situar a los objetos y seres en el tiempo y en el espacio, «se refieren a lugares, objetos y gestos». ${ }^{24}$ En DREM, los elementos que nos permiten ubicar el espacio y tiempo son pocos: en el tomo 7 nos damos cuenta de que la historia se lleva a cabo en el Distrito Federal. En cuanto al tiempo, las informaciones nos dan cuenta, a través del espacio y vestimenta de los personajes, que estamos en la época actual, hasta el tomo 6 no nos enteramos de que la historia se desarrolla en 2008, gracias a los carteles que aparecen, en donde se busca a Neve, quien se halla desaparecida.

En esta historia se representa muy poco el espacio urbano; dentro de sus elementos característicos localizados, podemos encontrar sendas, representadas por calles que, a pesar de todo, no nos proporcionan una idea clara de la ubicación exacta de los personajes ni del lugar en el que se desarrolla la historia.

También podemos observar los nodos ${ }^{25}$ en los paraderos de autobuses y el metro, a los que acuden los personajes para transportarse; aquí nos encontramos con la primer información que nos permite situar a los personajes: el autobús que toma el novio de Neve, Noah, para ir a visitarla, tiene un letrero que dice P. colorado, Águilas, Mixcoac, en esa misma escena, nos enteramos que ella vive en la calle Espigones de la Delegación Álvaro Obregón de la ciudad de México. Otro nodo que destaca es la escuela. En DREM no se dan referencias explícitas; sin embargo, las informaciones son suficientes ya para reconocer el lugar: la Escuela Nacional Preparatoria 8 plantel Miguel E. Schulz, ubicada en la ya mencionada delegación (lo confirmamos en el volumen 1, cuando Neve se baja del autobús en Barranca del Muerto). Por otro lado, el único hito ${ }^{26}$ que encontramos en toda la historia es el Ángel de la Independencia, que aparece en el volumen 7 y que nos confirma que la historia se desarrolla en la Ciudad de México.

su vez en índices e informaciones. Beristáin. H. Análisis estructural del relato literario. México, Universidad Nacional Autónoma de México, 1984, p. 30.

23 Talens, J. Op.cit., p. 47.

24 Beristáin, H. Op.cit., p. 41.

25 Son todos aquellos puntos estratégicos de la ciudad a los que puede ingresar el observador y constituyen los focos intensivos de los que parte o los que se encamina. Pueden ser ante todo confluencia, sitios de una ruptura en el transporte, un cruce o una convergencia de sendas, momentos de paso de una estructura a otra. LyNch, K. La imagen de la ciudad. La Habana, Ciencia y Técnica, 1970, p.91.

${ }^{26}$ Los hitos son otro tipo de punto de referencia, pero en este caso el espectador no entra en ellos, sino que le son exteriores. Por lo común se trata de un objeto físico, definido con bastante sencillez, por ejemplo, un monumento, un edificio, una señal, una montaña, algunos se encuentran distantes y es característico que se les vea desde muchos ángulos y distancias, son utilizados como referencias radiales, unos los encontramos fuera de la ciudad y otros son elementos locales, siendo visibles. Ibid., p. 98. 


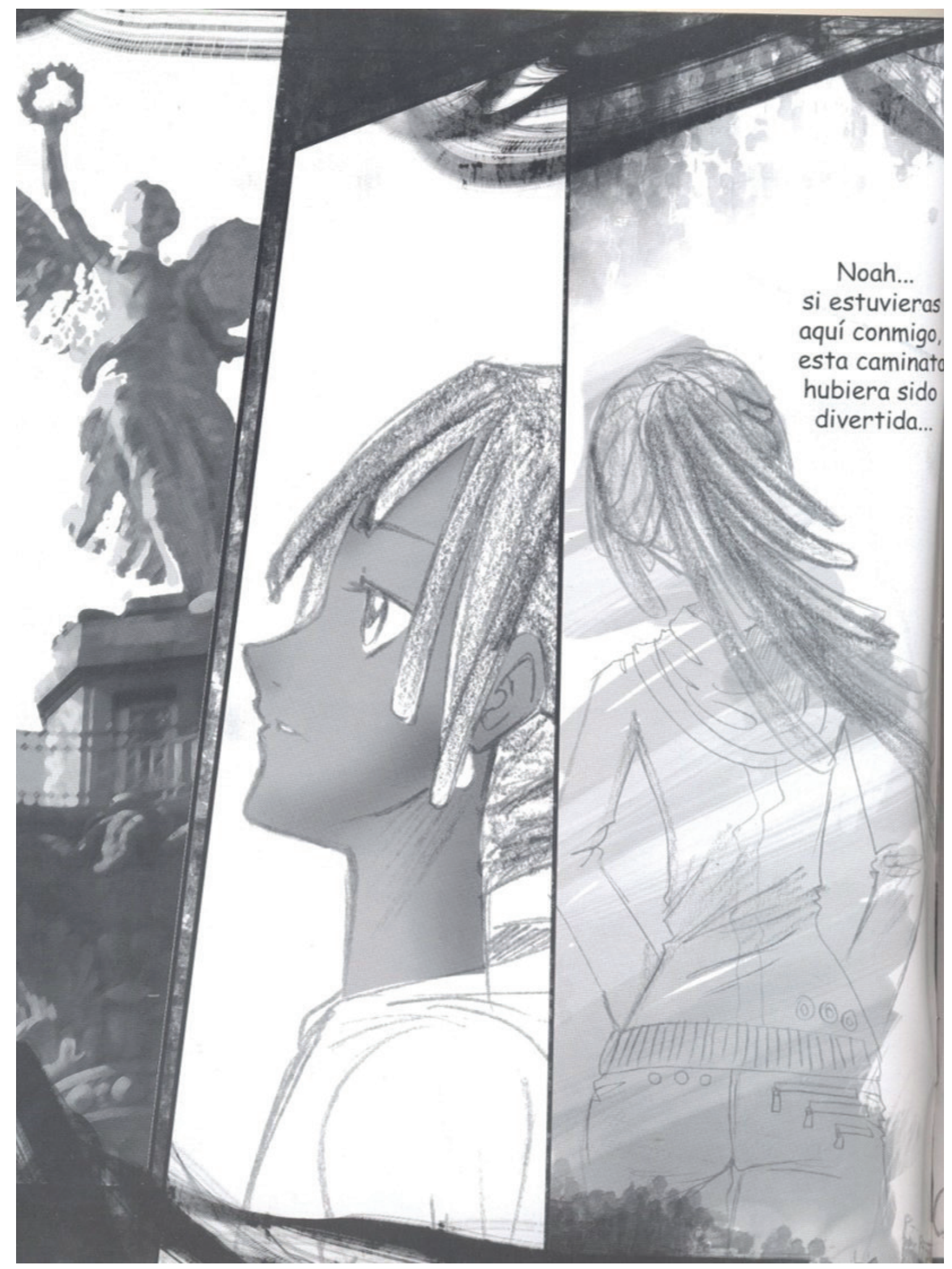

FIG. 2. Velasco Terán, L. DREM, 2008. 
Si el espacio urbano es poco representado en DREM, predominan los espacios de la casa, en donde se desarrollan la mayoría de vivencias de Neve. Se representa, por lo tanto, a la vivienda y el macroambiente que la rodea: características del vecindario, el tipo de comercios, la localización, superficie del área y estilo arquitectónico. En este caso de trata de una casa de dos pisos que sin embargo, remite a las adquiridas por medio de Infonavit; las calles cercanas son estrechas, con callejones en donde se refugia Neve luego de enterarse de la muerte de su madre. En cuanto a los comercios, se representa una tienda de abarrotes de nombre Churp.

Los índices por otro lado, «permiten al lector identificar, a partir de su conocimiento del mundo, las características físicas o psicológicas de los protagonistas». ${ }^{27}$ Generalmente son muy numerosos y variados. Sabemos algo acerca de la edad de Neve porque acude a una escuela preparatoria; el dato de su edad se confirma en el tomo 6, cuando aparecen anuncios en donde se reporta como desaparecida: Neve Midan Luna, $1.68 \mathrm{~m}$ de estatura, 17 años, cabello rubio en corte de capas y ojos púrpura.

Durante esta parte de la historia, el personaje viste pantalones a la cadera de corte acampanado, de moda en los años en los que el manga fue creado, usualmente es representada con distintos tipos de sudaderas y playeras con estoperoles, botones y correas. Contrario a su amiga Leely, Neve no suele usar ropa muy escotada. Psicológicamente, este personaje evoluciona y se transforma, el manga trata del proceso que lleva a Neve a aceptar los hechos dolorosos de su vida. Neve es una chica superficial, su mundo seguro gira en torno a su amiga Leely y al chico que le gusta, Noah; no es un personaje que tenga los pensamientos más profundos y, cuando comienza a tenerlos, los evade por las evidentes relaciones con la vida real que intenta evadir. Con todo, Neve evoluciona y se transforma, de su inseguridad y dudas pasa a la seguridad y el deseo de continuar su vida.

Neve: No puedo creer que te hayas ido... No me dejes sola... ahh... La luz sobre el agua... es algo en verdad maravilloso, lástima que pocas personas son capaces de apreciarlo. Qué extraño... Este lugar, se siente tan cálido como en mi antigua casa... Me hace sentir feliz, tranquila... Aquí me siento completa... ${ }^{28}$

Este es uno de los primeros pensamientos de Neve al enterarse de la muerte de su madre, la negación y la inconsciencia, su primer viaje al lugar del agua y oscuridad, a partir de donde iniciará su sueño. Por el contrario, al final el personaje ha crecido, admite lo ocurrido y se despide con amor de su ser querido. Los otros personajes que destacan por su importancia en las historia son Leely y Noah, la amiga y el novio de Neve. Es importante enfatizar que la Leely y el Noah que conocemos son solo más representaciones en la mente de Neve, la manera en la que los conoce y el modo en que en su sueño los elabora, con los que se siente segura y en situaciones agradables; los verdaderos Leely y Noah solo aparecen al final de la serie y por lo tanto, no podemos saber qué tanto evolucionan o si cambian realmente.

\footnotetext{
27 Beristáin, H. Op.cit., p. 39.

${ }^{28}$ Velasco Terán, L. DREM. México, n. ${ }^{\circ}$ (2008), pp. 3-6.
} 


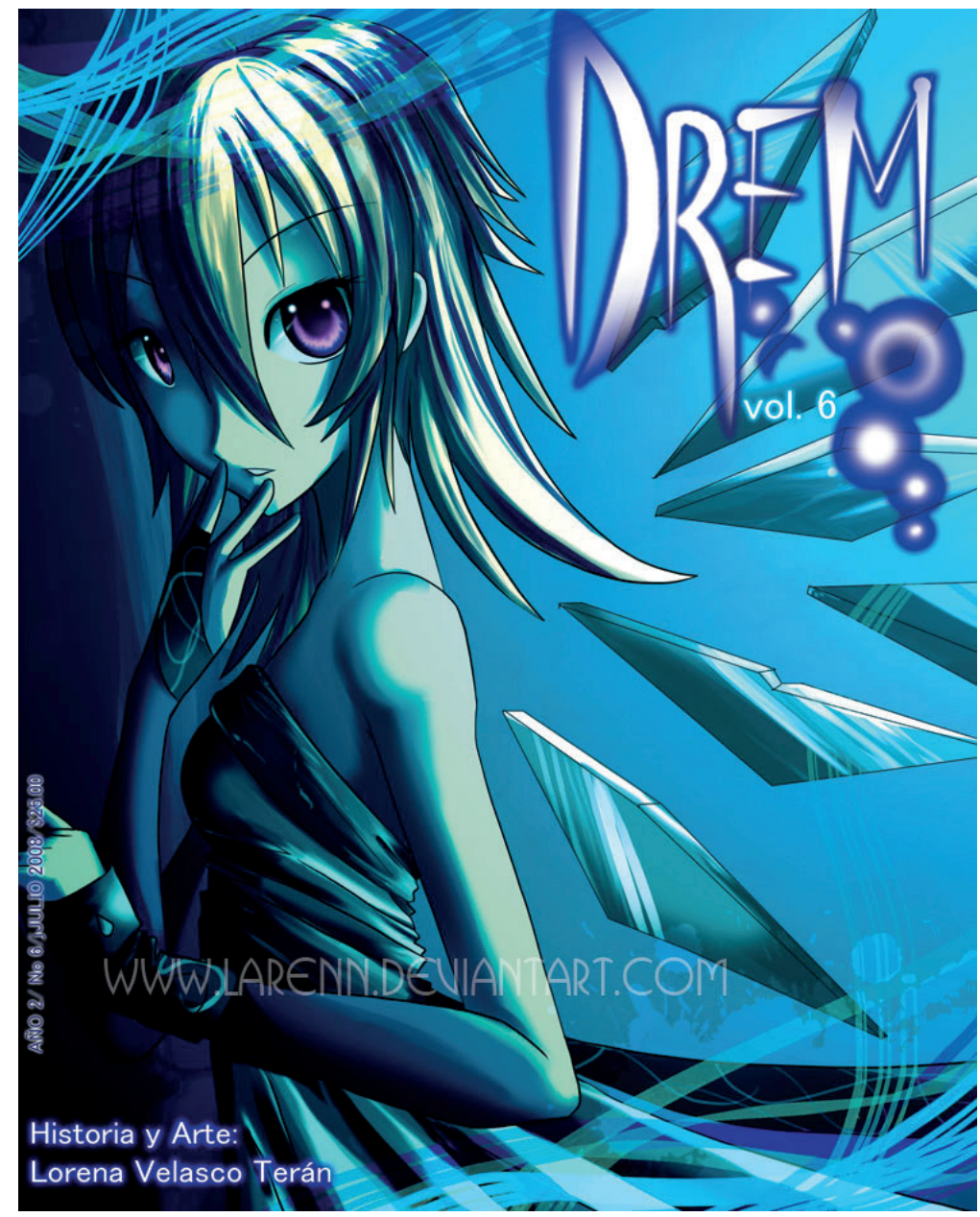

FIG. 3. VeLAsco Terán, L. DREM, 2008.

El siguiente nivel de análisis es el sintáctico, en el que se examinan las «relaciones de los signos entre sí», ${ }^{29}$ a través del análisis de las acciones realizadas a lo largo de la historia. En este nivel, observaremos las principales acciones que constituyen los nudos de la historia, así como las funciones que determinan las relaciones de los actantes ${ }^{30} \mathrm{y}$ sus respectivas matrices actanciales.

Las acciones del actante derivan de su papel dentro de la historia, así como de las relaciones que establece con los otros. Existen tres tipos generales de relación entre los personajes: desear, comunicar, luchar (participar). ${ }^{31}$ Cuando la perspectiva del actante cambia, cambia

${ }^{29}$ Talens, J. Op.cit., p. 43.

${ }^{30}$ Los actantes son personajes, objetos u abstracciones en un rol dado. Los actantes designan los roles fundamentales y abstractos en tanto que son susceptibles de funciones específicas, determinadas en una estructura actancial de opuestos Son funciones en el relato. SAniz, B. L. «Esquema actancial explicado», en Punto cero vol. 13, n. 15 (2008), p. 92.

${ }^{31}$ Camacho Morfín, T. La zoociedad en monitos. Historieta y cultura popular [tesis de licenciatura]. ENEP-Universidad Nacional Autónoma de México, 1993, p. 9. 
su función (y sus acciones) y por consiguiente sus relaciones con otros actantes; de esta consideración procede el sistema actancial, o matriz actancial, la cual consta de seis actantes o clases de actores representador por oposiciones binarias y conforme a los tres tipos de relaciones: deseo, comunicación y lucha.

El sujeto es el héroe del relato, que desea, ama, busca al objeto. El objeto es lo buscado, deseado por el sujeto, puede ser un personaje, una cosa, un valor. La categoría de destinador tiene como función la distribución del bien, el destinatario es el que obtiene de dicho bien. En el caso del ayudante y oponente, tenemos que el primero aporta auxilio orientado en el sentido del deseo del sujeto. El oponente crea obstáculos para que el sujeto no realiza su deseo.

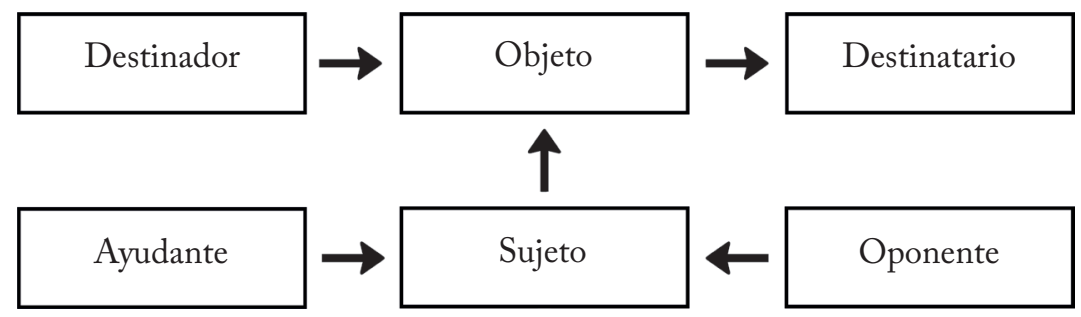

Para DREM la matriz actancial de la historia es la siguiente:

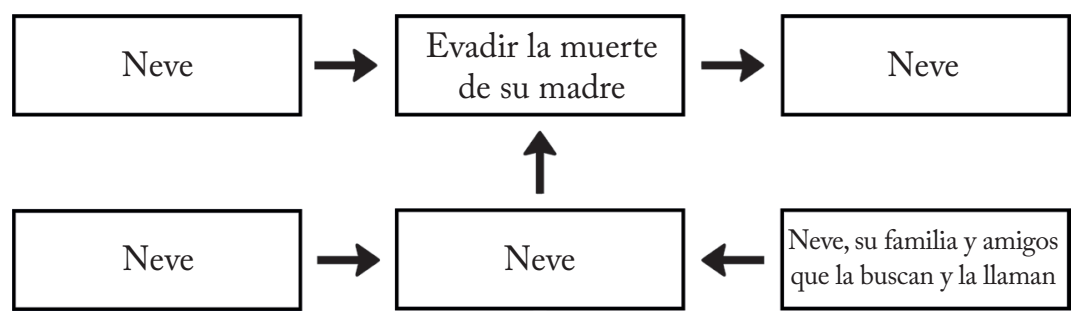

El sujeto de la historia es Neve y su objeto se centra en evadir la muerte de su madre, se tiene ella misma como destinataria, ya que de lograrlo, su dolor desaparecería; su ayudante es ella misma ya que crea la fantasía dentro de su sueño, donde los personajes y amigos son también parte de su yo. Como oponentes tiene a su familia y amigos que la buscan, y cuya angustia llega hasta ella en sueños; además ella misma es su oponente, porque una parte de su consciencia toma la forma de Leely y la incita a despertar de manera constante. Aparte de la matriz actancial de la historia, DREM consta de cuatro secuencias, cada una con su respectiva matriz actancial, las cuales, por cuestiones de espacio, no abordaremos en este artículo.

El último nivel que se estudiará es el pragmático, que Talens define como aquel que «analiza las relaciones que se establecen entre los signos y sus usuarios»; ${ }^{32}$ es aquí donde se examina el contexto en el que se produjo la obra así como las relaciones que establece el autor con

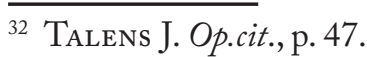


la misma. Este último nivel de análisis lo examinaremos en el siguiente apartado, cuando hablemos del contexto de las convenciones de cómics en el que se desarrolló como artista Lorena, así como los demás productos que ella diseña y elabora.

\subsection{Otros productos con estética japonesa}

El segundo aspecto que retomó Lorena Velasco Terán, al desarrollarse primero como aficionada y luego como creadora en el campo de las convenciones, es la fórmula de venta del manga, mediante la cual innovó estrategias que le permitieron obtener capital económico a la par del simbólico.

Lorena nació en el Distrito Federal en 1986, desde pequeña entró en contacto con el manga y anime debido a que su hermano mayor era asiduo visitante de las convenciones de cómics. Fue él quien la introdujo en el mundo del manga, y fue por él que empezó a dibujar. Lorena se desenvolvió en el campo de las convenciones; en primera instancia su posición fue como aficionada, por lo que su trayectoria estaba vinculada únicamente a la obtención del capital cultural objetivado, es decir, los propios productos, ya sea anime, manga o videojuegos; además de la obtención de capital simbólico o prestigio, con su habilidad para dibujar.

Este habitus primario se relacionó con su posición de aficionada, se creó a partir de experiencias personales y su personalidad como parte de sus estructuras subjetivas, y todo lo que ocurría en relación al manga y anime en la época en el aspecto objetivo. Fue un habitus estructurado a partir de la imagen fragmentaria de manga, anime, videojuegos y moda que formaron el acervo de lo visto, de lo conocido en cuanto a estética, narrativa y permanecieron en el inconsciente que crea y reproduce el habitus.

A los dieciséis años, en la preparatoria, Lorena entró en contacto con un grupo de jóvenes, quienes la invitaron a publicar sus historias en las convenciones. Dicho colectivo se denominó Estudio Luciérnaga. Fue en este periodo cuando Lorena publicó la primera versión de $D R E M$. A partir de ese momento Lorena mantuvo el interés por dar a conocer su historia, por lo que existen varias versiones de DREM. En 2007 Lorena y su compañero Mauricio Alberto Sánchez Serrano fundaron Estudio Syanne y en 2008 publicaron la última versión de DREM que analizamos en este artículo.

Si el habitus primario de Lorena se creó a partir de su posición como aficionada en el campo, su posterior cambio de fan a creadora lo modificó y su trayectoria se orientó a la generación de estrategias con la finalidad de obtener capital económico mientras de forma paralela obtenía capital simbólico con su obra. Bajo el sello de Syanne, Lorena no solo se dedica a publicar sus historias de manga, sino que oferta numerosos diseños de ropa y artículos basados en la estética del manga y creados por ella misma.

El ambiente en el que entró Lorena en su momento se caracterizaba por una fuerte competencia entre los diversos artistas de cómic, ya que se trataba de «grupos que pocas veces 
compartían los mismo intereses, y que cuando lo hacían, se consideraban competencia». ${ }^{33} \mathrm{~A}$ lo anterior, habría que agregarle el hecho de que al ser artistas de cómic, su posición en el campo se vinculaba más a la vanguardia que a las editoriales propiamente dichas, ${ }^{34}$ las estrategias, entonces, estaban fundadas en la denegación de la economía, la cual, aunque no sea total, tiende a darle predominio a la obtención de capital simbólico y no al económico. Dicha denegación significa, aparentemente, un rechazo a los intereses y beneficios comerciales, por ello, los agentes que forman parte del campo de consumo cultural, tomarán las conductas más antieconómicas y desinteresadas $;{ }^{35}$ con la finalidad de ganar más capital simbólico. Sin embargo, en este proceso, se obvia que la denegación económica utilizada como estrategia para obtener capital simbólico, no es total, la finalidad de obtener capital simbólico también está relacionada con la obtención de capital económico; el error era, por lo tanto, no ver al área de editoriales y stands como competencia, y los artistas no tomaban estrategias que deliberadamente se orientaran a la obtención de capital económico, aunque sí lo desearan, porque su habitus y su posición estaba de otro lado del campo y aparentemente buscaban otros fines.

Lorena, sin embargo, llegó a las convenciones decidida a obtener capital económico sin abandonar su lucha por el capital simbólico, por lo que en vez de ubicarse únicamente en el área de creadores, seguir las reglas del juego de ese lado, y aprender solamente dicho babitus, decidió transgredir las reglas del juego, jugar de ambos lados del campo y obtener ambos tipos de capital con la promoción de su historieta, la renta de un stand para ofrecer sus diseños de moda y productos creados por ella misma.

Sabíamos que a la gente no le interesan tanto los dibujantes y luego no llegan a esa área, entonces nosotros dijimos «no, nosotros hay que ponernos, aunque nos cueste más dinero y nos vamos a esforzar para estar donde está la gente y que nos quieran consumir [...]». Debo decir que cuando estábamos en Estudio Syanne éramos los únicos dibujantes que teníamos un stand de venta, no una mesa de dibujante, como que estábamos aparte de los dibujantes. ${ }^{36}$

De modo que lo que Lorena reestructuró, a su manera, fue la fórmula del mercado del manga japonés, el cual desde su país de origen comparte su público con otras industrias; las historias de manga exitosas, adaptadas al anime, vinculan a más industrias, como es el caso de la producción de videojuegos, merchandising, música y moda.

La fórmula magistral japonesa del éxito comercial consiste en un cuádruple mercado de anime, manga, videojuegos y merchandising, donde todos los productos se interrelacionan entre sí, provocando la movilidad del ciudadano entre los diferentes medios y fomentando el consumo. Un ejemplo paradigmático de este proceder es la rentable franquicia de Pokemon de la compañía Nintendo. ${ }^{37}$

${ }_{33}$ Gantús L. Op.cit., p. 228.

${ }^{34}$ No olvidemos que para esa fecha, entre 2007 y 2008, la historieta industrial ya estaba en completa decadencia.

35 Bourdieu, P. (2010). Op.cit., p. 154.

36 Castelli, I. Entrevista realizada a Lorena Velasco Terán en la Ciudad de México el 25 de agosto del 2016.

37 Santiago Iglesias, J. A. Op. cit., p. 368. 
A su modo, cuando Lorena y su compañero Mauricio fundaron Syanne, recrearon la formula comercial japonesa pero adecuada a su experiencia y cantidad de capital económico, por lo que apoyaron la venta de DREM y sus mangas posteriores con diseños de moda basada en la estética del visual kei y lo Kawaii.

Aunque nuestro principal objeto de estudio en estas páginas es el manga de DREM, es importante hacer mención de los demás productos que Estudio Syanne genera, principalmente por la siguiente razón: así como el manga no llegó solo a México, sino acompañado del anime, videojuegos y merchandising, lo que Lorena vio no fue solo manga, y por lo tanto, lo que diseña no se aboca a un solo producto: en Syanne podemos encontrar ropa, ilustraciones y merchandising. Como ya se dijo, Estudio Syanne se fundó en 2007, aunque la idea venía gestándose desde 2006: «Somos una empresa mexicana única en su clase, nos dedicamos al diseño de ropa y accesorios e ilustraciones», ${ }^{38}$ por lo tanto, en dicho espacio se pueden encontrar cómics, pósteres, camisetas, cuadernos, chamarras, vestidos, bolsas, calcomanías, separadores, mochilas, peluches, amigurumis, ${ }^{39}$ la mayoría basados en diseños de Lorena.

La ropa diseñada por Lorena al parecer es su principal producto de venta: sudaderas, camisetas, vestidos y faldas caracterizados por el uso del color negro combinado con gris, azul, morado y rojo; además, la mayor parte de los diseños se decora con asimetrías, hebillas, estoperoles y cintas. El tipo de moda que Lorena recrea y diseña se asocia directamente con el Visual Kei: el cual es

un género de la cultura popular japonesa y se refiere a un movimiento en el J-Rock (música) que se hizo popular en los comienzos de la década de los 1990. Esto no es tanto caracterizado como un género musical, sino por su énfasis en la expresión visual. Los miembros de la banda a menudo realizan cruces de género, usan maquillaje y ropa inspirada en el diseño visual del gótico, Punk y Glam Rock, así como juegos de computadora y anime japonés. ${ }^{40}$

Este tipo de moda, originalmente se ubicaba en una serie de productos que la autora vio y consumió en su época de fan, esta estética le llamó la atención porque la observaba principalmente en los ropajes que usaban los personajes femeninos en los videojuegos como Resident Evily en las ilustraciones de Masamune Shirow. ${ }^{41}$ Además de la ropa, Lorena diseña mercancía con estética Kawaii.

${ }^{38}$ Estudio Syanne: «Descripción de Estudio Syanne» en Facebook. Disponible en https://www.facebook. com/estudiosyanne/about/?entry point=page nav about item\&tab=page info [Consultado el 29 septiembre 2016].

39 Basado en una moda japonesa, se trata de muñecos tejidos con técnica de ganchillo, principalmente de animales.

${ }^{40}$ Наsнimoто, M. «Visual Kei Otaku Identity An Intercultural Analysis», en Intercultural Communication Studies, vol. Xvi, n. ${ }^{\circ} 1$ (2007), p. 87.

${ }^{41}$ Ilustrador y mangaka japonés, conocido por obras como Ghost in the Shell y Dominion Tank Police, la estética de sus diseños se vincula fuertemente al cyberpunk. 


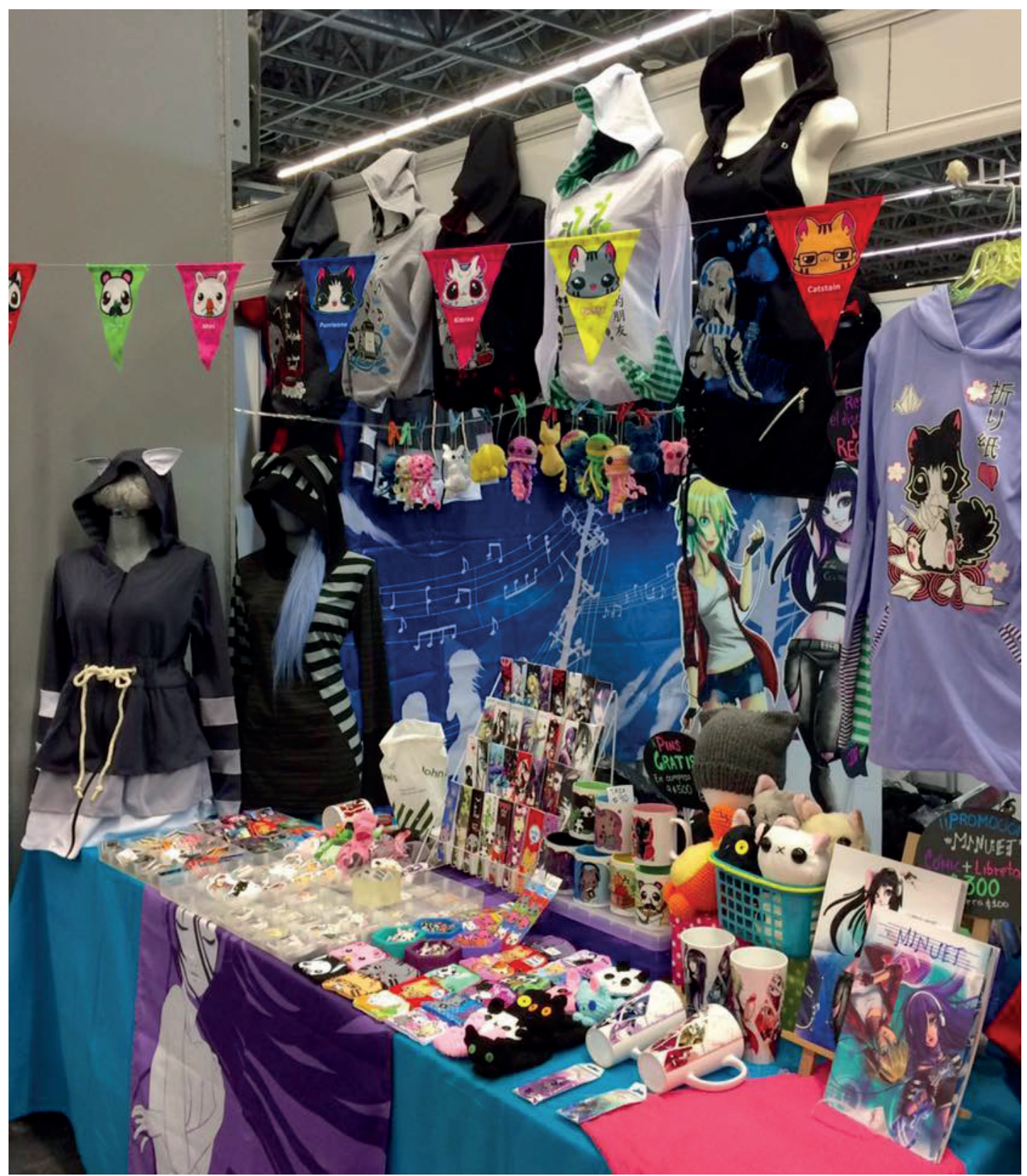

FIG. 4. Estudio Syanne, 2016.

Kawaii es un adjetivo japonés que significa bonito. La estética Kawaii consiste en la elaboración de productos ligados al imaginario del manga, caracterizados por representar personajes exacerbando aspectos expresivos y destacando la ternura. ${ }^{42}$ De modo que estos personajes forman parte de la estética del manga, anime y todos sus productos relacionados. A pesar de ser una moda común, parece no hacer atributos específicos que permitan reconocer a los productos Kawaii, sin embargo «un gran número de investigadores coinciden en afirmar que

${ }^{42}$ Santiago Iglesias, J. A. Op. cit., pp. 476-477. 
un objeto kawaii ha de ser suave y esponjoso, de formas redondeadas y colores pastel, con un diseño reducido y adorable, $y$ con multitud de pequeños adornos abalorios y decorativos.» ${ }^{43}$

Al igual que ocurrió con la elaboración de prendas y el desarrollo de un estilo de manga propio, la creación de productos con características kawaii en el caso de Lorena, se debe al tipo de habitus que desarrolló primero como fan y luego como creadora dentro del campo del manga en México, particularmente en las convenciones; en este caso, destaca el hecho de que además de los productos de merchandising, Lorena ha integrado esta estética a ropa con marcada influencia de Visual Kei, lo que genera un producto novedoso y particular.

\section{Conclusiones}

En este artículo sostuvimos que el manga mexicano DREM mezcla elementos gráficos propios del manga y los reestructura para crear una obra original y propia creada a partir de la gráfica japonesa pero con una historia que se sitúa en un contexto netamente mexicano. La manera en la que influyó la estética del manga en el caso de Lorena fue más compleja de lo que imaginamos debido a que este es un producto que se interrelaciona estrechamente con otros productos de las industrias culturales: anime, videojuegos y merchandising, por lo tanto, Lorena no solo reelaboró la gráfica del manga, sino también la moda y los productos de merchandising.

Las fuentes primarias de este artículo fueron los siete fascículos de DREM, así como entrevistas con su creadora. La revisión de fuentes secundarias como libros, hemerografía y material audiovisual nos llevó a comprender que este manga mexicano es resultado de un consumo racional, lo que llevó a la creación de una historia que reestructura elementos procedentes de la gráfica japonesa, los cuales integra en la historia con tintes psicológicos y oníricos. Debido a lo anterior, no compartimos la postura de Hiroki Azuma y Eiji Otsuka para quienes el consumo del manga y sus derivados es irracional y conduce al ser humano a la animalización, sino todo lo contrario.

¿Cómo es que DREM logra hibridar los elementos provenientes de dos tradiciones gráficas diferentes? Es debido a que existe una simpatía entre ambas ${ }^{44}$ que permite un punto de unión y la consecuente transposición de elementos diferentes, ya que «la presencia de lo híbrido ha de revelar parentesco entre las cosas más separadas». ${ }^{45}$ Este elemento o punto de unión, este atractor es el que «selecciona una u otra conexión, orienta uno u otro enlace o sugiere una u otra asociación entre los seres y las cosas». ${ }^{46}$ En el caso de México y Japón, el punto de unión sería que ambas culturas presentan amplias tradiciones gráficas en donde la

\footnotetext{
${ }^{43}$ Ibid., p. 481.

${ }^{44}$ Gruzinski, S. El pensamiento mestizo. Buenos Aires, Paidós, 2000, p. 188.

45 Ibid., p. 203.

${ }^{46}$ Ibid., p. 207.
} 
historieta ha fungido como un elemento nodal en la cultura popular; además de lo anterior, tanto en México como en Japón, su consumo ha sido, desde su origen, adulto.

Lo importante de DREM es que presenta un producto derivado de un consumo racional, en donde el público reinterpreta y reelabora los elementos que observa, los mezcla con su entorno y vida cotidiana y recrea nuevas formas, en este caso en relación a una historia, imagen y consumo. DREM y su autora sentaron bases en relación a la creación de un manga mexicano con características propias que además se apoya en la mercancía para mantenerse en juego con una base económica sólida. Esta última estrategia ha sido retomada por otras revistas que promueven la creación de manga mexicano con historias desarrolladas en el contexto propio de cada autor. ${ }^{47}$ Lo anterior permite una variedad cada vez mayor de manga mexicano que circula sobre todo en las convenciones de cómics, lo que da al público mejores opciones de consumo.

47 Revistas Doon Magazine y Kokoro. La primera se fundó en 2011, la segunda en 2013. Ambas producen mercancía como tazas, separadores y pósteres, relacionados con sus historias, lo que les permite sostener parte de los gastos de producción y circulación de las revistas. Además, emiten convocatorias periódicas para que los autores interesados en publicar sus historias, envíen su material ajustándose a las normas de publicación. 


\section{REFERENCIAS}

\section{- Hemerografía}

Velasco Terán, L. DREM. México, n. ${ }^{\circ}$ 1-7.

\section{- Bibliografía}

Azuma, H. Otaku. Animal database. Minessota, Universidad de Minessota, 2009.

Beristáin, H. Análisis estructural del relato literario. México, Universidad Nacional Autónoma de México, 1984.

Bourdieu, P. El sentido social del gusto, elementos para una sociología de la cultura. Buenos Aires, Siglo xxi, 2010.

—Las estrategias de la reproducción social. México, siglo XXI, 2011.

Bouissou, J. M. Manga. Historie et univers de la bande desinée japonaise. París, Philippe Picquier, 2010.

Camacho Morfín, T. La zoociedad en monitos. Historieta y cultura popular. [tesis de licenciatura]. ENEP-Universidad Nacional Autónoma de México, 1993.

Calabrese, O. La era neobarroca. Madrid, Cátedra, 1999.

Cerón Martínez, U. «Reconocimiento simbólico y poder en la obra de Pierre Bourdieu. El juego de las acreditaciones», en Revista de Investigación en Ciencias Sociales y Humanidades Cinteotl, n. ${ }^{\circ} 1$ (mayo de 2007).

De Los Reyes, A. (coord). La enseñanza del dibujo en México. México, Universidad Autónoma de Aguascalientes, 2014.

Gantús, L. La increíble y triste historia de la cándida historieta y la industria desalmada. México, Gantús Producciones, 2014.

Gruzinski, S. El pensamiento mestizo. Buenos Aires, Paidós, 2000.

Hasнimoто, M. «Visual Kei Otaku Identity An Intercultural Analysis» en Intercultural Communication Studies, vol. XVI, n. ${ }^{\circ} 1$ (2007).

Lynch, K. La imagen de la ciudad. La Habana, Ciencia y Técnica, 1970. 
Montiel, A. Teorias del cine, el reino de las sombras. Barcelona, Literatura y Ciencia, 1999.

McCloud, S. El arte invisible. Bilbao, Astiberri Ediciones, 2007.

Oтsuka, E. «An Unholy Alliance of Eisenstein and Disney: the fascist origins of Otaku Culture,» en Research Gate (enero de 2013), pp. 251-277. Disponible en https://www.researchgate.net/publication/259749564 An Unholy Alliance of Eisenstein and Disney The Fascist Origins of Otaku Culture [Traducción propia].

Ramírez Beltrán, C. J. «Modelo conceptual para determinar el impacto del merchandising visual en la toma de decisiones de compra en el punto de venta», en Pensamiento y gestión, n. 36 (2014), pp. 3-27.

Saniz, B. L. «Esquema actancial explicado», en Punto cero vol. 13, n. 15 (2008), pp. 91-97.

Santiago Iglesias, J. A. Manga, del cuadro flotante a la viñeta japonesa. Pontevedra, Grupo de Investigación dX5 Digital y Grafic Art Research, 2010.

TALENS, J. «Práctica artística y producción significante», en Elementos para una semiótica del texto artístico, Madrid, Cátedra, 1988.

\section{- Entrevistas}

Arceo, M. «La primera dama del manga en México-Heidi, un muestrario de temperamentos» en Santos Cómics, 21 de junio 2016. Disponible en https://rompeviento. tv/?p=9993.

Castelli, I. Entrevista realizada en la Ciudad de México el 25 de agosto del 2016 a Velasco Terán, L.

\section{- Páginas de internet}

E.S. «Descripción de Estudio Syanne,» en Facebook 29 septiembre 2016. Disponible en https://www.facebook.com/estudiosyanne/about/?entry point=page nav about item\&tab=page info. 